American Journal of Economics and Business Administration 1 (2): 194-205, 2009

ISSN 1945-5488

(C) 2009 Science Publications

\title{
A Theory of the Risks of Venture Capital Financing
}

\author{
Edmund H. Mantell \\ Department of Finance, Lubin School of Business, Pace University, \\ 1 Martine Avenue, White Plains, New York, USA, 10606
}

\begin{abstract}
Problem statement: There is no general theory analyzing how the time-varying cash flows of venture capitalist financing affect the likelihood of success of a new venture. This research addressed that lacuna in the literature. Approach: Research in the area of venture capital financing was needed because of the importance of new ventures as germinators of technological innovation. The research in this study developed a general economic theory quantifying the risk of venture failure associated with time-varying cash flows of financing. Each occasion when an entrepreneur made an overture to a venture capitalist to elicit a financing commitment was defined to be a distinct "solicitation event". The series of financial commitments elicited from venture capitalists were assumed to have the characteristics of independently distributed random variables. It was assumed that the entrepreneur must secure a minimal aggregate commitment in order to ensure development of the project; failure to secure that amount caused the venture to be aborted. The theory of stochastic processes was applied to derive the practical implications as regards the risk of abortion. Results: It was shown that the aggregate financing commitment secured by an entrepreneur in a finite time had stochastic properties corresponding to those of a statistical renewal process. The research derived limiting conditions on the probability that entrepreneur's venture will be aborted because of his failure to secure the minimal aggregate commitment. The main result was that if the number of solicitations by the entrepreneur is large and the financial commitments were independently distributed random variables with finite means and variances, the probability distribution governing venture survival is the Normal distribution. Conclusion: The study derived four analytical propositions quantifying the tradeoffs between the risk and the expected return associated with venture capital financing. The policy implications of the results imply the benefits of mitigating information asymmetry. Some of the risk faced by the entrepreneurs could be attenuated if information about the risk/return preferences of venture capitalists were known to the entrepreneurs prior to solicitation. Some of the risks faced by the venture capitalists could be attenuated if information about the risk/return characteristics of the proposed investment project could be accurately and transparently communicated to the venture capitalist during the solicitation event. If either or both of these information deficits were palliated, the market for venture capital would operate more efficiently.
\end{abstract}

Key words: Entrepreneurial solicitations, venture capital financing, stochastic processes, probability of entrepreneurial insolvency, renewal process

\section{INTRODUCTION}

The germination of corporate vitality via venture capital is growing rapidly. By the end of year 2001, companies financed with venture capital since the 1970s accounted for $5.9 \%$ of the jobs in the United States and $13.1 \%$ of US gross domestic product in year 2000 (National Venture Capital Association).

These statistics, as well as others that can be adduced, evidence the tremendous impact that venture capital has had on employment and revenue generation in the United States during the past thirty years. "Given that venture capital was less than one percent of US investment activity during most of the period studied, its impact is remarkable ${ }^{[30],}$,

In view of the growing significance of the venture capital industry in the US, it is odd that so little attention has been given to the development of a formal theory of entrepreneurial behavior in the venture capital solicitation process. There is a large body of literature describing the attitudes and the investment behavior of the venture capitalists ${ }^{[6-8,18,33]}$. There are empirical studies documenting the realized rates-of-return to the venture capitalists employing different exit strategies ${ }^{[2]}$. There is an abundant supply of how-to-do-it books and articles dispensing practical guidance to entrepreneurs 
seeking financing (An especially well known how-todo-it book is Pratt) ${ }^{[22]}$. There are books and articles describing the financial contracting process (A general recent survey is $\mathrm{Hart}^{[9]}$. A much more focused description of financial contracting in the venture capital industry is Sahlman ${ }^{[27]}$ ). I have not found any general theory purporting to analyze the intertemporal properties of entrepreneurial funding. The lacuna is confirmed by a very recently published study wherein the author commented "...though entrepreneurial firms are a pivotal source of new employment in Europe, the entrepreneur's perspective on capital acquisition is rarely discussed in the literature, ${ }^{\text {, } 26]}$. That author conducted a case study, consisting mainly if interviews with successful entrepreneurs. However, without a rigorous theory of the solicitation process, the statistics yielded by the data collected might "yield only a few banalities" "[19].

This study establishes a theory of the venture capital funding by focusing attention on the activities of the entrepreneur at the incipiency of the investment process: Namely the solicitation event.

A "solicitation event" is a series of activities wherein the entrepreneur (or the entrepreneurial group) searches for a venture capitalist to solicit, proposes an investment to a venture capitalist and elicits a financial commitment or, more frequently, a rejection. A series of such events constitutes the solicitation process. This way of describing a solicitation event makes it possible to characterize it as a binary-valued variable; i.e., either the entrepreneur secures a financial commitment, or he does not.

This study describes the series of solicitation events as the realization of random variables. The successes and the failures of the entrepreneurial group are shown to have characteristics conforming to those of a stochastic process. I exploit some of the properties of such processes to derive behavioral implications as well as inferences pertaining to the probability distributions governing the success of the funding solicitations.

\section{MATERIALS AND METHODS}

Synopsis of the venture capital funding process: From the perspective of the microeconomic theory of financial institutions, the venture capitalist is a kind of financial intermediary between entrepreneurs and the investing public $^{[3]}$. The venture capitalist manages funds for downstream investors (i.e., the buyers of the stock when and if, the business goes public) who are not interested in direct investment in high risk/high return investments. Without such financial intermediaries, the market for venture capital would tend to dry up. This is because relatively poorly informed investors who were drawn into failing investments would decline to provide venture capital finance. The investment allocation problems associated with risk and uncertainty are assigned to those persons who are willing and competent to manage them. Venture capitalists are sufficiently specialized and experienced in high-risk investments to cope with problems of information asymmetry. This management of information asymmetry tends to lead to the so-celled problem of adverse selection. Venture capitalists have been characterized as institutions that resolve information asymmetries ${ }^{[1,24]}$.

Venture capital firms often finance projects which, at the time of funding, have neither revenues nor even a product in existence ${ }^{[14]}$. However, an entrepreneur (or an organized group) will often approach venture capitalists (hereafter "VCs") for funding at different stages in the gestation of the nascent venture. The multiple stages of the finance solicitation activities have been adumbrated by Kozmetsky et al. ${ }^{[15]}$.

- Seed financing-capital provided to an entrepreneur to prove a concept. It may include product development but does not involve initial marketing

- Start-up financing-financing used in product development and initial marketing

- First-stage financing-financing provided to companies that have expended their initial capital (often in developing a prototype) and require funds to initiate commercial manufacturing and sales

- Second-stage financing-working capital used for the initial expansion of a company that is producing and shipping a product and has growing accounts receivable and perhaps inventories

- Third-stage financing-funds providing for major expansion of a company whose sales volume is increasing and that is breaking even or starting to show a profit

- Fourth-stage, mezzanine, or bridge financingcapital funds invested in a company expected to go public within six months to a year

When a VC makes a funding commitment to an entrepreneur it almost always entails staged financing. That is, the VC makes a firm commitment to offer a fraction of the funds needed, with the understanding that future funding is contingent on firm performance. This is financially equivalent to taking a sequence of call options on the entrepreneur's project. The VC then evaluates whether the project has reached its 
performance targets and decides whether to proceed with additional funding. Consequently, the initial funding commitment is seldom for $100 \%$ of the entrepreneur's needs.

To put the financial significance of these stages into practical perspective, in year 1999 "roughly 30\% apiece was invested (by VCs) in first and second rounds of financing and close to $40 \%$ was invested in third and later rounds, with the remainder (apparently close to zero) devoted to seed rounds"[31]. The multi-stage character of solicitation activities is embodied in the time series of solicitation events.

Assumptions characterizing the solicitation process: The solicitation process that is the subject of this study is characterized by a set of simplifying assumptions. These are enumerated below:

1. The entire time period during which the solicitation activities are carried out is called the funding solicitation period. The point in time that marks the inception of the solicitation activities is symbolized by $t_{0}$. The funding solicitation period is assumed to consist of $\mathrm{T}$ intervals of equal length: $\Delta \mathrm{t}_{\mathrm{i}}=\mathrm{t}_{\mathrm{i}}-\mathrm{t}_{\mathrm{i}-1}$ for $\mathrm{i}=1, \ldots ., \mathrm{T}$. In this study it is assumed that $\mathrm{T}$ is a large number

2. It is assumed that in each interval the entrepreneurial group solicits at least one source of venture capital funding. A solicitation event consists of three (or possibly four) distinct phases: (a) identify suitable VCs to be solicited, (b) make an overture to a suitable VC to determine whether he will entertain a full-blown proposal, (c) present a business plan to the $\mathrm{VC}$ who agrees to entertain the proposal and (d) carry out negotiations for funding and control. In order to simplify the model it is assumed that solicitation activities that are commenced in each time interval are completed in the same time interval

3. It is assumed that the funding decisions of the VCs who are solicited in each of the T time intervals are made during the same in the interval in which they are solicited

4. The length of the funding solicitation period is measured as $\sum_{\mathrm{i}=1}^{\mathrm{T}} \Delta \mathrm{t}_{\mathrm{i}}$

5. It is assumed that the terminal point of the solicitation period for this venture is immutable (The consequences of an immutable terminal point in the solicitation period has been vividly described by Sahlman ${ }^{[27]}$. "After picking himself up off the floor, the venture capitalist will begin a process of trying to educate (the entrepreneur) about the real world.... The terms of the (venture capitalist's) counteroffer will likely call for staged infusions of capital over time.... Remember that the venture is scheduled to run out of capital periodically; if it cannot raise capital at the second or third rounds, then it goes out of business and the entrepreneur is out of a job")

If an affirmative funding decision is made by a $\mathrm{VC}$ in the interval $\Delta \mathrm{t}_{\mathrm{i}}$, that decision is manifested as a monetary commitment in the same interval. The commitment may constitute a capital funding appropriation for a single period, or it may constitute serial commitments for funding the venture in specified amounts at predetermined points in future time. Whatever form it may take, the commitment secured in interval $\Delta \mathrm{t}_{\mathrm{i}}$ is symbolized by $\mathrm{I}\left(\Delta \mathrm{t}_{\mathrm{i}}\right)$. It is assumed that the entrepreneurial group regards the sequence of commitments $\left\{\mathrm{I}\left(\Delta \mathrm{t}_{\mathrm{i}}\right) \mid \mathrm{i}=1,2, \ldots \mathrm{T}\right\}$ as a stochastic process whose elements are independently distributed on the non-negative real line (there is some evidence of collaboration among venture capital firms in the form of syndication of their investments. For example, a 1994 study by Lerner $^{[16]}$ examines three rationales for the syndication of venture capital investments. He used a sample of 271 private biotechnology firms. Lerner found that syndication is commonplace, even in the first round investments. Syndication often ensures that the ownership stake of the venture capitalist stays constant in later venture rounds. For the purposes of the analyses in this paper a syndicate of VCs is defined as one VC acting independently of other VCs who are not members of the syndicate) Historically, only one out of 50-100 investment opportunities reviewed by any given $\mathrm{VC}$ has actually been financed (Tankersley ${ }^{[2]}$ and Zider ${ }^{[33]}$ "Even though the structure of venture capital deals seems to put the entrepreneurs at a steep disadvantage, they continue to submit far more plans than actually get funded, typically by a ratio of more than ten to one". This percentage has some empirical validity, as found by Maier and Walker ${ }^{[17]}$. Venture impact, 2007 page 10 stated: "For every 100 business plans that come to a venture capital firm for funding, usually only 10 or so get a serious look and only one ends up being funded"). To the extent that this historical statistic is stationary, most of the elements of the series $\left\{\mathrm{I}\left(\Delta \mathrm{t}_{\mathrm{i}}\right)\right\}$ will be equal to zero (One commentator has suggested that if an 
investment opportunity is rejected by a number of firms, it may get an "overshopped" reputation because VCs freely trade information and a turndown by one firm may influence others. See Tankersley ${ }^{[28]}$. Assumption (5) expressly precludes this behavior). In addition, the entrepreneurial group will recognize that they must expect to solicit many VCs in order to secure adequate funding. This translates to mean that $\mathrm{T}$ is likely to be a large integer

Another characteristic of the venture capital industry that affects the validity of Assumption (5) is that VC firms also protect themselves from risk by coinvesting with other VCs. It is the exception, not the rule, for one $\mathrm{VC}$ to finance an individual company entirely. Rather, venture firms prefer to have two or three VCs involved in most stages of financing ${ }^{[33]}$. This is a form of syndication (supra). A reason for this is that agency costs of investing are reduced when other reputable venture capitalists are syndicating a deal and the network allows an efficient transfer of information about competing firms and technologies. To the extent that this preference is ubiquitous in the community of VCs, it will tend to induce an increase in the number of VCs solicited by an entrepreneurial group. This attitude will also tend to cause $\mathrm{T}$ to be large

6. It is assumed that the members of the entrepreneurial group formulate homogeneous expectations about the parameters of the distributions governing the elements in the sequence $\left\{\mathrm{I}\left(\Delta \mathrm{t}_{\mathrm{i}}\right)\right\}$. The expected values of the aggregate commitments in each interval are symbolized by $\mathrm{E}\left[\mathrm{I}\left(\Delta \mathrm{t}_{\mathrm{i}}\right)\right]=\mu_{\mathrm{i}}$ and the variances of the aggregate commitments in each interval are symbolized by Variance of $\mathrm{I}\left(\Delta \mathrm{t}_{\mathrm{i}}\right)=\operatorname{var}_{\mathrm{i}}$

7. It is assumed that the entrepreneurial group allocates a budget of $\mathrm{B}$ dollars to underwrite the expenses of carrying on solicitation activities during the entire funding solicitation period. In each of the $\mathrm{T}$ intervals the group will spend a constant portion of the aggregate amount budgeted. The budget allocation in each solicitation interval is symbolized by $\mathrm{b} \leq \frac{\mathrm{B}}{\mathrm{T}}$

8. It is assumed that the entrepreneurial group has determined the minimum amount of financing required for a successful continuation of their project at the expiration of the funding solicitation period. That minimum is symbolized by $\mathrm{K}$ dollars. Funding at the minimal level does not guarantee success of the venture, but it is a sine qua non for success

9. It is assumed that if the group does not secure adequate funding on or before the expiration of the funding solicitation period the venture will be aborted

10. It is assumed that if the entrepreneurial group secures commitments equal to or exceeding $\mathrm{K}$ dollars prior to the expiration of the funding solicitation period, the solicitation activities will continue to the end of the funding solicitation period. To protect their investment or to compensate for the lack of available working capital from traditional sources, VCs provide later stage financing to their successful companies who otherwise would be unable to expand to a profitable maturity stage

Properties of the commitment process: Consider the financial status of the entrepreneurial group when it has completed solicitations in $t$ of the intervals, that is, there are T-t intervals remaining in which the entrepreneurial group will continue its solicitation activities.

Let $S_{t}$ represent the aggregate capital funding that has been committed to the group at the end of interval $t$. This is calculated as:

$\mathrm{S}_{\mathrm{t}}=\sum_{\mathrm{i}=1}^{\mathrm{t}} \mathrm{I}\left(\Delta \mathrm{t}_{\mathrm{i}}\right)$

The dollar magnitude of $\mathrm{S}_{\mathrm{t}}$ can be described in probabilistic language; the entrepreneur has made a sequence of draws from $t$ independent probability distributions. Each of those draws results in a nonnegative random variable, i.e., the dollar commitment. The sequence of dollar commitments sums to $\mathrm{S}_{\mathrm{t}}$. That sum consists of the realizations of $t$ random variables drawn from the process $\left\{\mathrm{I}\left(\Delta \mathrm{t}_{\mathrm{i}}\right) \mid \mathrm{i}=1,2, \ldots \mathrm{t}\right\}$. $\operatorname{Cox}^{[4]}$ describes this system as "an (ordinary) renewal process" (The analytical approach to renewal theory adopted by Cox casts it in terms of a population of "components" with "failure times" governed by a continuous random variable. He states: "It is again to be stressed that the terms component and failure-time can be given many different interpretations". In this paper the analogue of the " $n$th failure-time" (i.e., the $n^{\text {th }}$ renewal) consists of the investment commitment in the $\mathrm{n}^{\text {th }}$ solicitation interval).

Periodically (A recurring event $\xi$ is called periodic if there exists an integer $\lambda \succ 1$ such that $\xi$ can occur only at trials number $\lambda, 2 \lambda, 3 \lambda, \ldots$ The greatest $\lambda$ with this property is called the period of $\xi$. In this paper the 
periodicity of the process $\left\{S_{t}\right\}$ is a consequence of Assumption (1)), the sum $S_{t}$ is "renewed" by the random variable $I\left(\Delta t_{i}\right)$ such that in interval $\Delta t_{i}$ the first difference of the sum is $\mathrm{S}_{\mathrm{i}}-\mathrm{S}_{\mathrm{i}-1}=\mathrm{I}\left(\Delta \mathrm{t}_{\mathrm{i}}\right)$. A brief description of the application of renewal processes to finance can be found in Ziemba and Vickson ${ }^{[32]}$. A general treatment can be found in the monograph by Cox cited above.

Considered ex ante at the end of interval $t$, the net aggregate investment capital that will be available at the end of the funding solicitation period is a random variable. It can be expressed as Eq. 1:

$\mathrm{S}_{\mathrm{T}}=\sum_{\mathrm{i}-\mathrm{t}+1}^{\mathrm{T}} \mathrm{I}\left(\Delta \mathrm{t}_{\mathrm{i}}\right)+\mathrm{S}_{\mathrm{t}}+\mathrm{B}-\mathrm{bt}$

For any fixed value of $\mathrm{t}<\mathrm{T}$, ex post the partial sum $\mathrm{S}_{\mathrm{t}}$ is a known value. Thus we can condense the three constant terms on the right hand side of Eq. 1 and define:

$\mathrm{K}_{\mathrm{t}}^{*}=\left(\mathrm{K}-\mathrm{S}_{\mathrm{t}}\right)-(\mathrm{B}-\mathrm{bt})$

The quantity $\mathrm{K}_{\mathrm{t}}^{*}$ defined in Eq. 2 measures the marginal required commitment; that is, the aggregate commitment that must be secured by the entrepreneurial group in the future T-t intervals. The first parenthetical term on the right side of Eq. 2 represents the deficit remaining between (a) the minimum capitalization required for a launch of the venture and (b) the gross commitments to time t. The second parenthetical term represents the difference between the aggregate amount budgeted to underwrite the solicitation activities and the portion of it that will be expended by date $t$.

Expression (1) can now be adapted to the express the probability that the aggregate investment capital committed at the end of the funding solicitation time horizon will be inadequate to launch the venture, given the aggregate commitments to time t. That is to say, the conditional probability of undercapitalization calculated ex ante at time $t$ with ex post knowledge of commitments to that time. The probability is expressed as Proposition 1.

Proposition 1: If the number of solicitations is large and the capital commitments by the VCs are independently distributed random variables with finite means and variances, the probability that the venture will be aborted is a normally distributed function of the minimal aggregate capital commitment.
Proof: Pursuant to Assumption (9) above, the probability that the venture will be aborted is equal to the probability that the venture will be undercapitalized at the end of the solicitation period. The probability distribution is symbolized as $\mathrm{P}(\mathrm{)})$. The probability of undercapitalization can be written as Eq. 3:

$\mathrm{P}($ undercapitalization $)=\mathrm{P}\left(\mathrm{S}_{\mathrm{T}} \prec \mathrm{K}\right)=\mathrm{P}\left[\sum_{\mathrm{i}=\mathrm{t}+1}^{\mathrm{T}} \mathrm{I}\left(\Delta \mathrm{t}_{\mathrm{i}}\right) \prec \mathrm{K}_{\mathrm{t}}^{*}\right]$

Pursuant to Assumptions (1) and (5), the number of independently distributed random variables summed is T-t. If that number is large, then the sum satisfies a condition sufficient to invoke the Central Limit Theorem (i.e., CLT). The application of the CLT in this context states that the probability distribution governing the renewal equation $\sum_{\mathrm{i}=\mathrm{t}+1}^{\mathrm{T}} \mathrm{I}\left(\Delta \mathrm{t}_{\mathrm{i}}\right)$ is approximately Normal. The formal expression of the CLT entails some additional notation. Let $\bar{I}_{t}=\sum_{i=t+1}^{T} \mu_{i}$ and let $\sigma_{t}^{2}=\sum_{i=t+1}^{T} \operatorname{var}_{i}$. The former is the sum of the commitments expected in the remaining T-t solicitation events and the latter is the variance of that sum. Let the variable $\mathrm{Z}_{\mathrm{t}}$ be defined as:

$Z_{t}=\frac{\sum_{i=t+1}^{T} I\left(\Delta t_{i}\right)-\bar{I}_{t}}{\sqrt{\sigma_{t}^{2}}}$

The CLT states:

$\lim _{T-t \rightarrow \infty} P\left(Z_{t} \leq X\right) \cong F(X)$

where, $F($.$) symbolizes the cdf of the Normal$ distribution with a mean of 0 and a variance equal to 1 . This theorem allows us to derive an expression that is an approximate measure of the probability identified in Eq. 3. This is accomplished using simple algebra:

$$
\begin{aligned}
\mathrm{P}(\text { undercapitaliztion }) & =\mathrm{P}\left[\sum_{\mathrm{i}=\mathrm{t}+1}^{\mathrm{T}} \mathrm{I}\left(\Delta \mathrm{t}_{\mathrm{i}}\right) \prec \mathrm{K}_{\mathrm{t}}^{*}\right] \\
& =\mathrm{P}\left[\overline{\mathrm{I}}+\sigma_{\mathrm{t}} \mathrm{Z}_{\mathrm{t}} \prec \mathrm{K}_{\mathrm{t}}^{*}\right] \\
& =\mathrm{P}\left[\mathrm{Z}_{\mathrm{t}} \prec \frac{\mathrm{K}_{\mathrm{t}}^{*}-\overline{\mathrm{I}}_{\mathrm{t}}}{\sigma_{\mathrm{t}}}\right] \\
& \cong \mathrm{F}\left(\frac{\mathrm{K}_{\mathrm{t}}^{*}-\overline{\mathrm{I}}_{\mathrm{t}}}{\sigma_{\mathrm{t}}}\right)
\end{aligned}
$$

This completes the proof of Proposition 1. 
It is a property of all cumulative probability distributions that they are monotone non-decreasing functions of their argument (s). Thus, in this context it is obvious that any increase in the argument $\mathrm{X}_{\mathrm{t}}=\left(\mathrm{K}_{\mathrm{t}}^{*}-\overline{\mathrm{I}}_{\mathrm{t}}\right) / \sigma_{\mathrm{t}}$ will lessen the likelihood that the venture will secure its capitalization requirements.

Perhaps less obvious is the effect on the probability of undercapitalization of a change in the variance of the randomly distributed commitments in the remainder of the solicitation period, ceteris paribus. This issue bears on the behavior of the entrepreneurial group in carrying out its solicitation activities subsequent to time t. The implications of the CLT can be summarized in Proposition 2.

\section{Proposition 2:}

a. If the expected aggregate commitment exceeds the marginal required commitment, an increase in the variance of the aggregate commitment will increase the probability of undercapitalization

b. If the expected aggregate commitment is less than the marginal required commitment, an increase in the variance of the aggregate commitments will lessen the probability of undercapitalization

c. If the expected aggregate commitment equals the marginal required commitment, a change in the variance of the aggregate the future commitment will have no effect on the probability of undercapitalization

Proof: The proof of Proposition 2 proceeds by analyzing the partial derivative of the argument of the Normal cdf with respect to $\sigma_{\mathrm{t}}$, that is, taking the partial derivative of $X_{t}$ w.r.t. $\sigma_{t}$, we have:

$$
\frac{\partial X_{t}}{\partial \sigma_{t}}=\frac{\overline{\mathrm{I}}_{\mathrm{t}}-\mathrm{K}_{\mathrm{t}}^{*}}{\sigma_{\mathrm{t}}^{2}}
$$

It is obvious that $\operatorname{sign}\left[\partial \mathrm{X}_{\mathrm{t}} / \partial \sigma_{\mathrm{t}}\right]=\operatorname{sign}\left[\overline{\mathrm{I}}_{\mathrm{t}}-\mathrm{K}_{\mathrm{t}}^{*}\right]$. Recall that $\overline{\mathrm{I}}_{\mathrm{t}}$ represents the expected value of the sum of the randomly distributed commitments in the future $\mathrm{T}-\mathrm{t}$ periods. Also recall that $\mathrm{K}_{\mathrm{t}}^{*}$ represents the marginal required commitment. The following inferences are immediate:

a. If the aggregate expected commitment at time $t$ exceeds the marginal required commitment, then $\partial X_{t} / \partial \sigma_{t} \succ 0$

b. If the aggregate expected commitment at time $t$ is less than the marginal required commitment, then $\partial \mathrm{X}_{\mathrm{t}} / \partial \sigma_{\mathrm{t}} \prec 0$ c. If the aggregate expected commitment at time $t$ is equal to the marginal required commitment, then $\partial \mathrm{X}_{\mathrm{t}} / \partial \sigma_{\mathrm{t}}=0$

Pursuant to the strictly monotonic property of the Normal cdf, an increase in $X_{t}$ will increase the probability of undercapitalization. Likewise, a decrease in $X_{t}$ will lessen the probability of undercapitalization. The direct implication of monotonicity is that if the variance of the aggregate future commitments increases, ceteris paribus, the probability of undercapitalization will be increased when the sum of their expected values exceeds the target funding.

The probability of undercapitalization will decrease when the variance of future commitments increases, ceteris paribus, if target funding exceeds the sum of the expectations. This completes the proof of Proposition 2.

Behavioral implications of proposition 2: The behavioral implications of proposition 2 reflect the collective attitude towards risk manifested by the entrepreneurial group. It is well beyond the scope of this study to undertake a comprehensive discussion of the definition and the feasibility of establishing a collective attitude towards risk. This study assumes that the members of the group agree to act as if they shared a common attitude.

At the threshold of the behavioral analysis it will be useful to prescind the different manifestations of risk faced by the entrepreneurial group. One apparent risk is the risk that the group will fail to secure aggregate commitments that are required to launch the venture; that is, the risk that $S_{t} \prec K$. That risk can be called the terminal risk.

The other kind of risk is the uncertainty manifested in the variation of the interim cash flow commitments antedating the terminal point of the funding solicitation period. That risk is measured by the elements of the series $\left\{\sigma_{t}^{2} \mid t=1,2, \ldots . T\right\}$.

The reason for distinguishing between these two manifestations of risk is to establish a group utilityordering relation between them. As between these two manifestations of risk, it is assumed that the entrepreneurial group assigns primacy to the terminal risk. The collective group attitude regarding the terminal risk can be expressed in terms of the behavior aimed at attaining the objective of the group: The group adopts a policy of managing and carrying out the solicitation process in order to minimize the probability that the venture will fail to meet its capitalization requirements at the terminal point of the funding solicitation period. All other objectives of the group are 
subordinated to that primary objective. The group may manifest risk-aversive or risk-seeking attitudes only to the extent that those attitudes do not motivate behavior that is inconsistent with attainment of the group's primary objective.

Behavioral implications of a group risk-aversive attitude: Assume that the collective group attitude is one of risk aversion. This is construed to mean that the group will avoid any purposeful action that causes an increase in the riskiness of the cash flow of the future commitments, ceteris paribus. This presumed attitude reflects recent research in the area of managerial attitudes and practices for managing risk. It embodies the psychological approach developed by, inter $\mathrm{alia}^{[12,5,10,29]}$. All these papers are case studies adducing empirical evidence respecting managerial attitudes towards defining, measuring and managing risk). The fundamental notion is one of "loss aversion" ---notably the avoidance of the maximum conceivable loss. The maximum loss, in the context of this study, would be the failure by the entrepreneur to elicit aggregate commitments sufficient to meet its capitalization requirements at the terminal point of the funding solicitation period. A failure of that magnitude results in the death of the investment project. From the perspective of the entrepreneur, nothing could be worse. That attitude has been empirically studied in several recent publications.

Given this construction, Proposition 1 implies the following: A risk-aversive group will manage its future solicitation activities in such a way as to cause an increase in the riskiness of the future commitments if the expected value of those aggregate commitments exceeds the marginal required commitment. This is an instance in which a risk-aversive group will seek out additional risk in its interim cash flow in order to lessen the terminal risk of failing to meet its targeted objective.

This counterintuitive result is a direct implication of part (b) of Proposition 1. The riskiness of the aggregate future commitments is measured by the variance of the sum of those randomly distributed commitments. Proposition 1(b) establishes that an increase in that variance will lessen the probability of undercapitalization, given the inequality specified in that part of the proposition.

Behavioral implications of a group risk-seeking attitude: A group risk-seeking attitude is construed to mean that the group will conduct its solicitation activities in such as way as to cause an increase in the riskiness of the cash flow of the future commitments, ceteris paribus.

Given this construction, Proposition 1 implies the following behavior: If the expected aggregate commitment exceeds the marginal required commitment, a risk-seeking group will carry on its solicitation activities in such a way as to lessen the riskiness of the cash flow of future commitments. This counterintuitive result is a direct implication of part (a) of Proposition 1.

Behavioral implications of group risk-neutrality: A collective attitude of risk-neutrality means that the group regards the changes in the variability of the future commitments as irrelevant to its solicitation activities, ceteris paribus.

Proposition 1(c) implies that if the expected aggregate commitment is equal to the marginal required commitment, the group will not alter its solicitation behavior in response to changes in the riskiness of the future commitments unless those changes produce an inequality of the two capital amounts.

Mean-variance analysis when the solicitation intervals are independent random variables: Assumption 1 defined the solicitation intervals as fixed and of equal length. This study relaxes that assumption to enhance the verisimilitude of the theory.

The Synopsis of this study suggested that there are at least three and perhaps four distinct phases of the solicitation process in each interval. The amount of time allocated to phase (a) is entirely controlled by the entrepreneurial group (one well-known entrepreneur with a track record of successful experiences in raising venture capital delivered a speech in which he revealed to incipient entrepreneurs (and others) some of the fund-raising practices that worked well for him.. First on his list of "tips" was an exhortation to "... carefully target four or five venture firms that have investment strategies consistent with your company's needs". Hoffstein ${ }^{[11]}$; the amount of time allocated to phases (b), (c) and (d) is only partially controlled by the group. The search activity in phase (a), to the extent that it is carried out carefully and with due attention to the kind of information to be discovered, will often represent the most time consuming portion of the total solicitation activities (An example of the "due attention" to the information discovered by the search is the avoidance of approaching a later stage investor if the entrepreneurial group is looking for seed money). 
Am. J. of Economics and Business Administration, 1 (2): 194-205, 2009

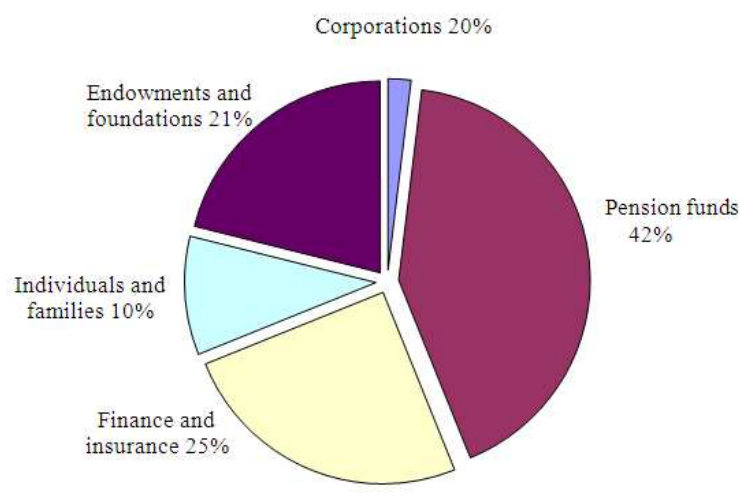

Fig. 1: Distribution of the sources of entrepreneurial funding in the US in $2003^{[30]}$

The systematic component of the solicitation interval reflects the deliberations and the search activities carried out by the entrepreneurial group to identify VCs to approach. As a general matter, there are at least six distinct sources of funding, each with its own special interests and attitudes towards risk. Figure 1 displays the relative distribution of the sources of entrepreneurial funding in year 2003. The entrepreneur must allocate sufficient time to identify the optimal VCs to approach.

To the extent that the $\mathrm{VC}$ participants in the process exercise control over the tempo of the solicitation activities in phases (b-d), the time required to complete the solicitation in each interval cannot be known by the entrepreneurs with certainty ex ante. The entrepreneurial group regards each solicitation interval as consisting of the sum of a systematic part and a randomly distributed part.

Hereafter the solicitation intervals $\left\{\Delta \mathrm{t}_{\mathrm{i}} \mid \mathrm{i}=1,2, \ldots\right\}$ are assumed to be i.i.d. random variables with $\mathrm{E}\left[\Delta \mathrm{t}_{\mathrm{i}}\right]=\Delta \overline{\mathrm{t}}$ and Variance $\left[\Delta \mathrm{t}_{\mathrm{i}}\right]=\sigma_{\Delta \mathrm{t}}^{2}$. I assume the entrepreneurial group knows (or can estimate) the numerical values of these parameters.

Define the random interval $T_{n}$ as the cumulative time elapsed between the inception of solicitation activity (at time $\mathrm{t}_{0}$ ) and the conclusion of the solicitation event in the interval $\Delta \mathrm{t}_{\mathrm{n}}$. That cumulative elapsed time interval is calculated as:

$\mathrm{T}_{\mathrm{n}}=\sum_{\mathrm{i}=1}^{\mathrm{n}} \Delta \mathrm{t}_{\mathrm{i}}$

Assumption 5 is also amended. Hereafter the elements of the process of the capital commitments
$\left\{\mathrm{I}\left(\Delta \mathrm{t}_{\mathrm{i}}\right)\right\}$ are $\quad$ i.i.d. where $\quad \mathrm{E}\left[\mathrm{I}\left(\Delta \mathrm{t}_{\mathrm{i}}\right)\right]=\mu \quad$ and Variance $\left[\mathrm{I}\left(\Delta \mathrm{t}_{\mathrm{i}}\right)\right]=\sigma^{2}$.

The counterpart elements of the processes $\left\{\Delta \mathrm{t}_{\mathrm{i}} \mid \mathrm{i}=1,2, \ldots\right\}$ and $\left\{\mathrm{I}\left(\Delta \mathrm{t}_{\mathrm{i}}\right) \mid \mathrm{i}=1,2, \ldots \mathrm{t}\right\}$ are not, in general, independent. The correlation between corresponding elements is symbolized by:

$$
\rho=\frac{\operatorname{Cov}\left[\Delta \mathrm{t}_{\mathrm{i}}, \mathrm{I}\left(\Delta \mathrm{t}_{\mathrm{i}}\right)\right]}{\sqrt{\sigma_{\Delta \mathrm{t}}^{2} \sigma^{2}}}
$$

I assume $\operatorname{Cov}\left[\Delta \mathrm{t}_{\mathrm{i}}, \mathrm{I}\left(\Delta \mathrm{t}_{\mathrm{j}}\right)\right]=0$ for $\mathrm{i} \neq \mathrm{j}$.

Define the stochastic process $\left\{\mathrm{N}\left(\mathrm{T}_{\mathrm{i}}\right) \mid \mathrm{i}=1,2, \ldots\right\}$ as a counting process such that $\mathrm{N}\left(\mathrm{T}_{\mathrm{i}}\right)$ represents the total number of solicitation events completed up to time $T_{i}$. Formally, $\mathrm{N}\left(\mathrm{T}_{\mathrm{i}}\right)$ has the following properties:

(i) $\mathrm{N}\left(\mathrm{T}_{\mathrm{i}}\right)>0$ for all $\mathrm{i}$

(ii) $\mathrm{N}\left(\mathrm{T}_{\mathrm{i}}\right)$ is integer valued

(iii) If $\mathrm{j}<\mathrm{i}$, then $\mathrm{N}\left(\mathrm{T}_{\mathrm{j}}\right)<\mathrm{N}\left(\mathrm{T}_{\mathrm{i}}\right)$

(iv) For $\mathrm{j}<\mathrm{i}, \mathrm{N}\left(\mathrm{T}_{\mathrm{i}}\right)-\mathrm{N}\left(\mathrm{T}_{\mathrm{j}}\right)$ equals the number of solicitation events that have occurred in the interval $\mathrm{T}_{\mathrm{i}}-\mathrm{T}_{\mathrm{j}}$

These properties suffice to establish $\mathrm{N}\left(\mathrm{T}_{\mathrm{i}}\right) \mid \mathrm{i}=1$, $2, .$.$\} as a renewal process { }^{[25]}$. Now we can define a stochastic process that measures the aggregate capital commitments that have been secured from the total number of VCs in all the solicitation events up to time $\mathrm{T}_{\mathrm{n}}$.

The notation can be simplified by omitting the subscript appended to $T_{n}$. Hereafter, $N(T)$ will signify the total number of VCs who have been solicited in the arbitrary interval $\left[\mathrm{t}_{0}, \mathrm{~T}\right]$. The aggregate commitments in that interval is:

$\mathrm{S}_{\mathrm{T}}=\mathrm{I}\left(\Delta \mathrm{t}_{1}\right)+\mathrm{I}\left(\Delta \mathrm{t}_{2}\right)+\ldots+\mathrm{I}\left(\Delta \mathrm{t}_{\mathrm{N}(\mathrm{T})}\right)$

The stochastic process $\left\{S_{T}\right\}$ is called a renewal reward process by $\operatorname{Ross}^{[25]}$ and a cumulative renewal process by $\mathrm{Cox}^{[4]}$ and Karlin ${ }^{[13]}$. All these researchers analyze parametric and other characteristics of this process. Cox displays the limiting properties of the mean and variance of $\{\mathrm{N}(\mathrm{T})\}$ for large $\mathrm{T}$ as follows:

$$
\mathrm{E}[\mathrm{N}(\mathrm{T})] \approx \frac{\mathrm{T}}{\Delta \overline{\mathrm{t}}} \text { and } \operatorname{Var}[\mathrm{N}(\mathrm{T})] \approx \mathrm{T} \frac{\sigma_{\Delta \mathrm{t}}^{2}}{(\Delta \overline{\mathrm{t}})^{3}}
$$


The counterpart parameters of $\left\{\mathrm{S}_{\mathrm{T}}\right\}$ for $\mathrm{T} \rightarrow \infty$ are given by $\mathrm{Cox}^{[4]}$ as follows:

$\mathrm{E}\left[\mathrm{S}_{\mathrm{T}}\right]=\mathrm{T} \frac{\mu}{\Delta \overline{\mathrm{t}}}$

$\operatorname{Var}\left[\mathrm{S}_{\mathrm{T}}\right]=\mathrm{T}\left[\frac{\sigma_{\Delta \mathrm{t}}^{2}}{\Delta \overline{\mathrm{t}}}+\sigma_{\Delta \mathrm{t}}^{2} \frac{\mu^{2}}{(\Delta \overline{\mathrm{t}})^{3}}-2 \sigma \sigma_{\Delta \mathrm{t}} \frac{\mu}{(\Delta \overline{\mathrm{t}})^{2}} \rho\right]$

Equation 6 can be substituted into Eq. 7 to express the variance of $\left\{\mathrm{S}_{\mathrm{T}}\right\}$ as a function of its expected value. The expression is written in Eq. 8:

$\operatorname{Var}\left[\mathrm{S}_{\mathrm{T}}\right]=\frac{1}{\Delta \overline{\mathrm{t}}}\left[\frac{\sigma_{\Delta \mathrm{t}}^{2}}{\mathrm{~T}}\left[\mathrm{E}\left(\mathrm{S}_{\mathrm{T}}\right)\right]^{2}-2 \sigma \sigma_{\Delta \mathrm{t}} \mathrm{E}\left(\mathrm{S}_{\mathrm{T}}\right) \rho+\mathrm{T} \sigma^{2}\right]$

Equation 8 establishes that the variance of $\left\{\mathrm{S}_{\mathrm{T}}\right\}$ is a quadratic function of its expected value, inter alia. For arbitrary numerical values of the parameters $\Delta \overline{\mathrm{t}}, \sigma_{\Delta \mathrm{t}}$ and $\sigma$, the shape of the locus of Eq. 9 is determined by the algebraic sign of the correlation between the solicitation intervals and the commitments secured in those intervals. Figure 3 illustrates the relationship between risk and expected return.

Figure 2 displays three members of a family of loci that differ from each other only with respect to a single parameter; namely the algebraic sign of the correlation between the randomly distributed solicitation interval [i.e., $\Delta \mathrm{t}_{\mathrm{i}}$ ] and the randomly distributed capital commitment secured in that interval [i.e., $\left.\mathrm{I}\left(\Delta \mathrm{t}_{\mathrm{i}}\right)\right]$. The Fig. 3 shows how the variance of the aggregate commitments at time $\mathrm{T}$ is functionally related to the expected value of that aggregate at the same time, assuming different algebraic signs of the correlations.

Generally, the loci are shaped as one would expect; namely sloping upward to the right. This is merely a graphic confirmation of the proposition that as the expected value of the aggregate commitments increases, its riskiness likewise increases. There is nothing remarkable in that result. However, the ordering of the curves implies a less obvious result; namely that as the correlation decreases, ceteris paribus, the riskiness increases. Compare, for example, a case where the capital commitment is statistically independent of the solicitation interval with the case where the two are positively correlated. Then for any arbitrary expected aggregate, the riskiness will be larger if the correlation is independent than if the correlation is positive. The loci displayed in Fig. 2 suggest inferences summarized in Proposition 3.

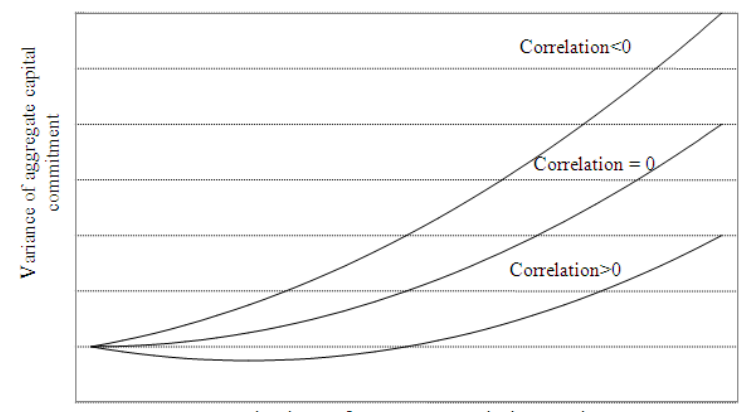

Expected values of aggregate capital commitments

Fig. 2: Level curves displaying the risk/return tradeoff for different correlations between the randomly distributed solicitation interval and the randomly distributed finance commitment in the interval

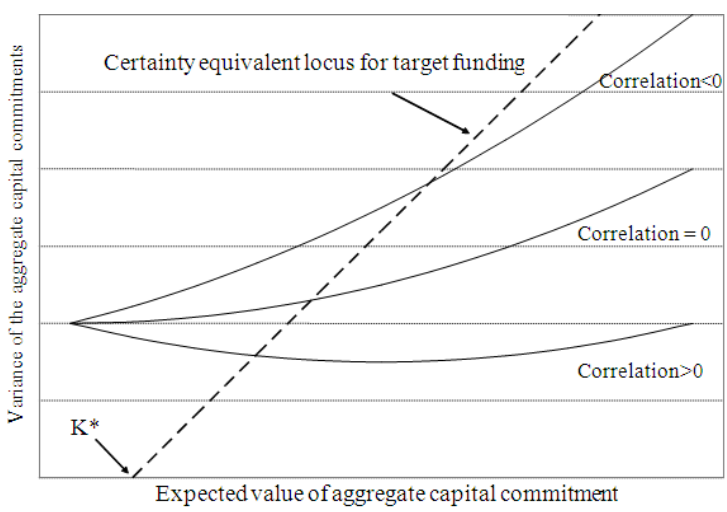

Fig. 3: Level curves of the variance showing the certainty equivalent varying with the correlation

Proposition 3: Given arbitrary values for three parameters: The mean solicitation interval, the variance of the solicitation interval and the variance of the randomly distributed capital commitments:

a. If the randomly distributed investment commitments are not positively correlated with time allocated by the entrepreneur to solicitation of those commitments, then the variance of the aggregate capital commitments is a monotone increasing function expected value of the aggregate capital commitment

b. If the randomly distributed investment commitments are positively correlated with time allocated by the entrepreneur to solicitation of those commitments, then variance of the aggregate capital commitments is initially a decreasing function and then an increasing function of the expected value of the aggregate capital commitments 
As a practical matter, one would expect that if an entrepreneurial group allocates more time and effort to the solicitation process, ceteris paribus, the individual capital commitments that the group can expect to secure will likewise increase, i.e., $\rho>0$. The counterintuitive implication of part (b) of Proposition 3 is that for some range of increases in the expected aggregate commitments, the riskiness of the aggregate capital commitment decreases.

Solicitation behavior for constant absolute risk aversion: Define a collective utility function for the entrepreneurial group as $\mathrm{U}(\mathrm{X})$ where $\mathrm{X}$ is a monetary amount. Let $\mathrm{U}$ be a three-times continuously differentiable function that assigns to its argument a collective utility for the entrepreneurial group. I assume that the function $U$ has the properties $U^{\prime}>0$ and $U^{\prime \prime}>0$. These properties of the aggregate utility function suffice to define the group's collective attitude towards risk.

If $\mathrm{X}$ is a random variable with an expected value symbolized by $\bar{X}$, then the so-called "coefficient of absolute risk aversion" is defined as $\theta(\bar{X})=-U(\bar{X}) / U^{\prime}(\bar{X})$. The usefulness of the coefficient of absolute risk aversion in this context is that it can be applied to identify the certainty equivalent of the uncertain outcome of the solicitation process.

Milgrom and Roberts ${ }^{[20]}$ explain that the certainty equivalent "...is the amount of income, payable for certain, that the (decision maker) regards as equivalent in value to the original, random income".

Let $\bar{S}_{\mathrm{T}}$ symbolize the certainty equivalent of $\mathrm{S}_{\mathrm{T}}$. That certainty equivalent can be calculated as (Milgrom and Roberts ${ }^{[20]}$ for a derivation of Eq. 9:

$\bar{S}_{\mathrm{T}}=\mathrm{E}\left[\mathrm{S}_{\mathrm{T}}\right]-\frac{1}{2} \theta\left(\mathrm{E}\left[\mathrm{S}_{\mathrm{T}}\right]\right) \operatorname{Var}\left(\mathrm{S}_{\mathrm{T}}\right)$

Where:

$\theta\left(E\left[S_{T}\right]\right)=-\frac{U^{\prime \prime}\left(E\left[S_{T}\right]\right)}{U^{\prime}\left(E\left[S_{T}\right]\right)}$

The certainty equivalent can be used to identify the mean and the variance of the aggregate capital commitment in the solicitation process implied by the correlation between the randomly distributed solicitation intervals and the random commitments secured in those intervals. In order to achieve this it is necessary to assume that the coefficient of absolute risk aversion is a non-negative constant hereafter symbolized by $\theta$ (considered from a behavioral perspective, constancy of the coefficient of absolute risk aversion is construed to mean that the risk premium that an entrepreneur would pay to eliminate a given amount of variance does not depend on the expected level of the aggregate commitment). If the entrepreneur assigns a fixed value $\mathrm{K}^{*}$ as a certainty equivalent, then Eq. 9 graphs as a straight line that can be superimposed on the loci displayed on Fig. 1. The result of that superposition appears in Fig. 3.

On Fig. 3 the dashed straight line is the graphic representation of the entrepreneur's certainly equivalent symbolized by Eq. 9. For any fixed value of capital, say $\mathrm{K}^{*}$, the dashed line shows the combination of the expected aggregate commitment/risk of commitment that the entrepreneur identifies as the certainty equivalent of $\mathrm{K}^{*}$. That is to say, at any point on the dashed line the entrepreneur would be indifferent between the fixed capital commitment $\mathrm{K}^{*}$ and a randomly determined aggregate commitment with an expected value/standard deviation given by the coordinates of the point on the line.

The certainty equivalent locus intersects each of the level curves associated with different correlations. For a fixed value of the certainty equivalent $\mathrm{K}^{*}$, it can be shown that the slope of the certainty equivalent locus is equal to $\sqrt{\frac{2}{\theta}}$. This implies that the slope of the certainty equivalent locus will decrease as the coefficient of absolute risk aversion increases, ceteris paribus. The behavioral implications of the geometry can be summarized in the following Proposition 4 .

Proposition 4: For a fixed certainty equivalent of the aggregate capital commitment, the mean and the variance of the aggregate capital commitment display the following properties:

a. If the correlation between the solicitation intervals and the capital commitments secured in those intervals is not positive, an increase in the entrepreneur's coefficient of absolute risk aversion will be associated with a larger mean and variance

b. If the correlation between the solicitation intervals and the capital commitments secured in those intervals is positive, an increase in the entrepreneur's coefficient of absolute risk aversion will be associated with a larger mean and a variance that first decreases and then increases

Part (a) of Proposition 4 has a counterintuitive sense; it suggests that as the entrepreneur's aversion to 
risk increases, ceteris paribus, he will carry out the solicitation activities in such a way as to result in an increase in the expectation and the uncertainty of the aggregate capital commitments. But this inference is strictly true only in the (arguably) unrealistic cases where the correlations between the time allocated to the solicitation events is not positively correlated with the capital commitments secured by those events.

In the most plausible scenario where the correlation is positive, namely Part (b) of the Proposition, Fig. 3 demonstrates that an increase in absolute risk aversion is associated with a larger expected value and a smaller variance for a range of different certainty equivalents.

\section{RESULTS AND DISCUSSION}

This study examines the risk-return relationships in a scenario wherein an entrepreneur solicits financial commitments from a series of venture capitalists. The four propositions derived in this study are based on the stochastic properties of the sequence of solicitation events as well as on the risk-attitudinal characteristics of the entrepreneur. The study applies ergodic theorems to derive statistical and behavioral inferences bearing on the parameters of the stochastic processes characterizing the solicitation events.

A main result of this study is Proposition 1; it derives a limiting probability distribution governing the likelihood that an entrepreneur will succeed in soliciting from venture capitalists the financial commitments that he needs to launch his venture.

Propositions 2 and 3 exploit the properties of the stochastic process of solicitation events to derive inferences bearing on the relationship between the variation in the series of capital commitments and the entrepreneur's expectation of aggregate financing.

Proposition 4 construes the ways in which the stochastic properties of the solicitation events influence the solicitation behavior of the entrepreneur. That proposition applies the theory of certainty equivalents and the coefficient of absolute risk aversion to show that changes in either of these attitudinal parameters will affect the tradeoff between the risk and the expected return in the solicitation process.

Implications for policy: The policy implication of the conclusions pertains to the problematic consequences of information asymmetry. On the one hand, some of the uncertainty faced by the entrepreneurs could be attenuated if information about the risk/return preferences of VCs were known to the entrepreneurs prior to solicitation. On the other hand, some of the risks faced by the $\mathrm{VCs}$ could be attenuated if information about the risk/return characteristics of the proposed investment project could be accurately and transparently communicated to the $\mathrm{VC}$ during the solicitation event. If either or both of these information deficits were palliated, the market for venture capital would operate more efficiently. How might the palliation be effected?

To the extent that the venture capital industry has the characteristics of a public good, governmental intervention might be justified as a means of mitigating some of the problems posed by the information asymmetry. The establishment of an information depository, operated by a disinterested governmental authority, could help to disseminate information among investors as well as entrepreneurs.

\section{CONCLUSION}

The study derived four analytical propositions quantifying the trade-offs between the risk and the expected return associated with venture capital financing. The policy implications of the results imply the benefits of mitigating information asymmetry. Some of the risk faced by the entrepreneurs could be attenuated if information about the risk/return preferences of venture capitalists were known to the entrepreneurs prior to solicitation. Some of the risks faced by the venture capitalists could be attenuated if information about the risk/return characteristics of the proposed investment project could be accurately and transparently communicated to the venture capitalist during the solicitation event. If either or both of these information deficits were palliated, the market for venture capital would operate more efficiently.

\section{REFERENCES}

1. Admati, A.R. and P. Pfleiderer, 1994. Robust financial contracting and the role of venture capitalists. J. Finance, 49: 371-403. DOI: $10.2307 / 2329157$

2. Barry C.B., C.J. Muscarella, W.I.I.I. Peavy and M.R. Vetsuypens, 1999. The role of venture capital in the creation of public companies. J. Fin. Econ., 27: 447-472. DOI: 101016/0304-405X(90)90064-7

3. Chan, Y.S., 1983. On the positive role of financial intermediation in allocation of venture capital in a market with imperfect information. J. Finance, 38: 1543-1569. DOI: $10.2307 / 2327586$

4. Cox, D.R., 1962. Renewal Theory. 1st Edn., John Wiley and Sons, Inc., New York., ISBN: 041220570X, pp: 142. 
5. Dickson, G.C., 1981. A comparison of attitudes towards risk among business managers. J. Occup. Psychol., 54: 157-165.

6. Ehrlich, S.B., A.F. DeNoble, T. Moore and R.R. Weaver, 1994. After the cash arrives: a comparative study of venture capital and private investor involvement in entrepreneurial firms. J. Bus. Ventur., 9: 67-83. DOI: 10.1016/0883-9026(94)90027-2

7. Gorman, M. and W.A. Sahlman, 1989. What do venture capitalists do? J. Bus. Ventur., 4: 231-249. DOI: 10.1016/0883-9026(89)90014-1

8. Haar, N.E., J. Starr and I.C. MacMillan, 1988. Informal risk capital investors: investment patterns on the east coast of the USA. J. Bus. Ventur., 3: 11-30. DOI: 10.1016/0883-9026(88)90027-4

9. Hart, O., 2001. Financial contracting. J. Econ. Literat., 39: 1079-1101. DOI: 10.2139/ssrn.269241

10. Helliar, C.V., A.A. Lonie, D.M. Power and C.D. Sinclair, 2002. Managerial attitudes to risk: a comparison of scottish chartered accountants and UK managers. J. Int. Account. Audit. Taxat., 11: 165-190. DOI: 10.1016/S1061-9518(02)00068$\mathrm{X}$

11. Hoffstein, G.B., 1996. Raising venture capital. Vital Speeches Day, 52: 366-370.

12. Kahneman, D. and A. Tversky. 1979. Prospect theory: An analysis of decision under risk. Econometrica, 47: 263-292. DOI: 10.2307/1914185

13. Samuel, K. and H.M. Taylor, 1975. A First Course in Stochastic Processes. 2nd Edn., Academic Press Inc., New York, ISBN: 0123985528, pp: 557.

14. Andrei, K., 2001. Valuation and Control in Venture Finance. J. Finance, 56: 565-588. DOI: 10.1111/0022-1082.00337

15. Kozmetsky, G., M.D. Gill and R.W. Smilor, 1985. Financing and Managing Fast-Growth Companies. 1st Edn., DC Heath and Company, Lexington, Mass, ISBN: 0669094811, pp: 348.

16. Lerner, J., 1994. The syndication of venture capital investments. Finance Manage., 23: 16-27. DOI: $10.2307 / 3665618$

17. Maier, J. and D. Walker, 1987. The role of venture capital in financing small business. J. Bus. Ventur., 2: 203-215. DOI: 10.1016/0883-9026(87)90009-7

18. Mason, C.M. and R.T. Harrison, 1995. Closing the regional equity gap: The role of informal venture capital. Small Bus. Econ., 7: 153-173. DOI: 10.1007/BF01108688

19. Miles, M.B. and A.M. Huberman, 1985. Qualitative Data Analysis: An Expanded Sourcebook. 2nd Edn., Thousand Oaks, Sage Pub, CA., ISBN: 0803955405, pp: 402.
20. Milgrom, P. and J. Roberts, 1992. Economics, Organization and Management. Prentice-Hall, Inc., Englewood Cliffs, New Jersey, ISBN: 0132246503, pp: 621.

21. National Venture Capital Association, 2001. Based on a study prepared by DRI-WEFA and commissioned by the NVCA. http://www.nvca.org

22. Schutt, D., 2009. Pratt's Guide to Venture Capital Sources. SDC Publishing, New York., ISBN 0979627834, pp: 1834.

23. Prowse, S.D., 1998. The economics of the private equity market. Economic Review of the Federal Reserve Bank of Dallas. http://www.docstoc.com/docs/documentpreview.aspx?doc_id=3627559

24. Reid, G.C., 1999. The application of principalagent methods to investor-investee relations in the UK venture capital industry. Venture Capital, 1: 285-302. DOI: 10.1080/136910699295820

25. Ross, S.M., 2001. Introduction to Probability Models. 10th Edn., Academic Press Inc., New York, ISBN: 0123756863, pp: 800

26. Saetre, A.S., 2003. Entrepreneurial perspectives on informal venture capital. Venture Capital, 5: 71-94. DOI: $10.1080 / 1369106032000062731$

27. Sahlman, W.A., 1988. Aspects of financial contracting in venture capital. J. Applied Corporate Finance, 2: 23-36. DOI: 10.1111/j.17456622.1988.tb00163.x

28. Tankersley, G.J., 1993. How to Choose and Approach a Venture Capitalist. In: Pratt's Guide to Venture Capital Sources, Schut, D. (Ed.). SDC Publishing, New York, ISBN: 0979627834, pp: 41-43.

29. Terpstra, R.H., D.A. Ralston and S. Bazen, 1993. Cultural influences on the risk taking propensity of United States and Hong Kong managers. Int. J. Manage., 10: 183-194.

30. National Venture Capital Association, 2007 Venture "Impact, Global Insight. 3rd Edn., National Venture Capital Association, Boston, Mass, pp: 78.

31. Venture One, 1999. Venture Capital Industry Report. Boston, USA., pp: 95.

32. Ziemba, W.T. and R.G. Vickson, 1975. Stochastic Optimization Models in Finance. Academic Press, Inc., New York, ISBN: 981256800X, pp: 756

33. Zider Bob, 1998. How venture capital works. Harvard Bus. Rev., 76: 131-140. DOI: $10.1225 / 98611$ 